\title{
Urdimento
}

Revista de Estudos em Artes Cênicas E-ISSN: 2358.6958

\section{O que performances e seus estudos têm a ensinar para a teoria da performatividade de gênero?}

Leandro Colling

\section{Para citar este artigo:}

COLLING, Leandro. O que performances e seus estudos têm a ensinar para a teoria da performatividade de gênero? Urdimento, Florianópolis, v. 1, n. 40, mar./abr. 2021.

do) DOI: http:/dx.doi.org/10.5965/1414573101402021e0200 
O que performances e seus estudos têm a ensinar para a teoria da performatividade de gênero?

\title{
Resumo
}

Leandro Colling

O texto problematiza a distinção entre performance de gênero e performatividade de gênero através de uma performance artística de Pêdra Costa e de vários textos dos estudos da performance. O autor defende que, ao invés de contrapor performance e performatividade, é necessário enfatizar o que existe entre essas duas dimensões que, em especial na arte feminista e/ou das dissidências sexuais e de gênero, são indissociáveis.

Palavras-chave: Performatividade de gênero. Performance. Estudos queer.

What do the performing arts and studies of artistic performances have to teach for gender performativity theory?

\begin{abstract}
The text problematizes the distinction between gender performance and gender performativity through an artistic performance by Pêdra Costa and several texts of performance studies. The author argues that, instead of opposing performance and performativity, it is necessary to emphasize what exists between these two dimensions that are inseparable, especially in both feminist and or in sexual and gender dissent arts.
\end{abstract}

Keywords: Gender performativity. Performance. Queer studies.

¿Qué las performances y sus estudios tienen que enseñar para la teoría de la performatividad de género?

\section{Resumen}

El texto problematiza la distinción entre performance de género y performatividad de género a través de una performance artística de Pêdra Costa y varios textos de los estudios de la performance. El autor argumenta que, en lugar de oponerse performance y la performatividad, es necesario enfatizar lo que existe entre estas dos dimensiones que, especialmente en el arte feminista y/o de la disidencia sexual y de género, son inseparables.

Palabras clave: Performatividad de género. Performance. Estudios queer.

${ }^{1}$ Professor permanente do Programa Multidisciplinar de Pós-graduação em Cultura e Sociedade e professor colaborador do Programa de Pós-Graduação em Estudos Interdisciplinares sobre Mulheres, Gênero e Feminismo. Universidade Federal da Bahia (UFBA). Integrante do NuCuS - Núcleo de Pesquisa e Extensão em Culturas, Gêneros e Sexualidades. leandro.colling@gmail.com. Revisão: Ricardo dos Santos Batista

(6) http://lattes.cnpq.br/9841032316581104 (iD https://orcid.org/0000-0002-0519-2991 
Para responder às críticas de que a identidade de gênero, em sua teoria da performatividade de gênero, teria um status voluntarista, Judith Butler, em determinadas ocasiões, propôs uma diferenciação entre performance e performatividade de gênero. Nessa distinção, performance seria aquela realizada pelas artistas drag, que se caracterizaria por um ato limitado, produto de uma vontade ou de uma eleição de quem a realiza. Já a performatividade de gênero não seria caracterizada pela eleição ou agência do sujeito, mas pelo efeito repetido da norma, ainda que essas repetições nem sempre sejam realizadas da maneira como as normas desejam. "É um erro reduzir a performatividade à performance" (Butler, 2002, p. 69). Neste texto pretendo, a partir de alguns estudos da performance e de uma performance artística, problematizar essa sentença de Butler.

No entanto, não farei uma apresentação exaustiva da teoria da performatividade de gênero². Apenas a título de breve explicação para os propósitos deste artigo, vale destacar que Butler destaca o caráter compulsório do gênero, mas também considera que algumas pessoas rejeitam essa compulsoriedade e transgridem as normas. Nas palavras dela:

[...] a performatividade deve ser compreendida não como um 'ato' singular ou deliberado, mas, ao invés disso, como uma prática reiterativa e citacional pela qual o discurso produz os efeitos que ele nomeia. O que, eu espero, se tornará claro no que vem a seguir é que as normas regulatórias do 'sexo' trabalham de uma forma performativa para constituir a materialidade dos corpos e, mais especificamente, para materializar o sexo do corpo, para materializar a diferença sexual a serviço da consolidação do imperativo heterossexual (Butler, 2008, p. 154).

\footnotetext{
${ }^{2}$ Fizemos isso em outro texto (Colling, Arruda e Nonato, 2019), no qual explicamos a teoria da performatividade de gênero, criada por Judith Butler (2002, 2003), tratamos das principais críticas que a autora recebeu e, por fim, evidenciamos como determinadas bixas afeminadas e fechativas transitam entre performance e performatividade, o que nos deu a ideia de nomear essas experiências como perfechatividades de gênero. Verificamos que algumas bixas afeminadas negociam entre distintas performances/performatividades de gênero, entre mais intencionais e calculadas, realizadas nos momentos em que elas sabem que precisam endurecer para não sofrer violências, e momentos em que elas podem fazer a sua fechação, quando se sentem mais seguras com as amigas, e as realizadas em outros momentos diários, quando elas não estão nem duras e nem propriamente sendo fechativas. No entanto, em todos os momentos aquele corpo afeminado e estranho está presente e fala, mesmo quando endurece ou tenta endurecer. Ou seja, não dá para estabelecer fronteiras rígidas entre esses distintos momentos performativos, mas eles se diferenciam e se conectam, às vezes são mais intencionais e, às vezes, seguem o ritmo das repetições constitutivas. Dessa forma, naquele texto anterior, evidenciamos que a distinção entre performance e performatividade de gênero, utilizada por Judith Butler, merece ser relativizada, mas ali pensamos performance no sentido amplo e antropológico (Schechner, 2012). Agora irei contrapor uma performance artística e vários estudos da performance com a teoria da performatividade de gênero.
} 


\section{Uma performance de gênero e sexualidade}

Compartilho a seguir uma breve narrativa sobre uma performance de Pêdra Costa realizada no Museu de Arte Contemporânea de Barcelona (MACBA). Assisti de_colon_isation part III: the bum bum cream - part III na noite do dia 10 de outubro de 2019. Pêdra Costa, artista do Brasil ${ }^{3}$ que vive em Berlim, diz que a proposta dessa sua obra é questionar a colonização e também os crimes cometidos pela Igreja Católica contra pessoas sodomitas durante a Inquisição4 .

Na capela do MACBA, Pêdra chegou vestindo um roupão preto e um sapato de salto alto da mesma cor. Deu boa noite e disse que iria dar uma aula. Tirou o roupão e ficou apenas com uma cueca jockstrap e começou a passar um creme em todo o corpo. Logo descobriríamos que o creme fazia referência a um produto que teria sido inicialmente criado nos Estados Unidos, feito com guaraná e açaí brasileiros, para tonificar a bunda das mulheres. O cheiro adocicado se espalhou pelo local. Pêdra pediu para uma pessoa da plateia passar o produto em suas costas. Depois esfregou bem o creme em todo o corpo. A colonização atinge todos os recantos de nossos corpos, pensei momentos depois ao refletir sobre o que tinha presenciado.

Em seguida, Pêdra dançou por vários minutos ao som do funk Vai balançando o bumbum. A música parou, uma pessoa ajudou Pêdra a tirar os sapatos. Um aparelho passou a projetar imagens, diretamente na bunda da performer, de uma propaganda sobre o tal produto, com uma pessoa falando em língua inglesa. Terminada a projeção, Pêdra enfiou um "dildo câmera" no seu ânus. Enquanto as imagens do seu esfíncter anal eram projetadas em uma tela, leu alguns trechos do Manifesto O Cu do Sul - The Kuir Sauvage, de sua autoria. Naquela noite, leu o seguinte texto:

As investigações sobre o cu são teóricas e práticas, sempre. A teoria está na pele e a prática vem da vida. A teoria só existe se existe a experiência. Só se transforma se passa pelo corpo. O cu do sul é movimento. As restrições e os sistema rígidos do corpo não fluem em esses estudos. Não

${ }^{3}$ Pêdra ficou conhecida através da banda Solange, tô aberta!. Para conhecer a fase inicial de sua carreira, ver o documentário Cuceta - a cultura queer de Solange Tô Aberta, de Cláudio Manuel, disponível em https://www.youtube.com/watch?v=WTDgw0Ms5Cs. Acesso em: 5 abr. 2020.

${ }^{4}$ As explicações são da própria artista no vídeo https://vimeo.com/228368662. Acesso em: 4 abr. 2020. 
lutamos contra nada. Nossas lutas sempre foram derrotadas. Já aprendemos sobre isso na história do mundo. Somos feiticeiras e curandeiras. Nosso baile e nossa ginga é nossa luta. Nossa forma de amar, jogar, está em conexão com nossa comunidade. Sempre somos coletivos. Nunca individuais. A astúcia é a base de toda a nossa vida contra o projeto colonial. A astúcia não se aprende nem se ensina. Nosso conhecimento nunca seria reconhecido se não fosse apropriado pelo conhecimento dos corpos brancos e/ou europeizados. Nossas vozes não são audíveis, portanto, temos toda a autonomia e autoridade para fundar tais estudos. Por mais que tentamos, nunca seremos autorizados como campo de conhecimento pela branquitude. Não necessitamos sua aprovação. Avançamos criticando as fantasias coloniais sobre nossos corpos e especificamente cus. Nossa crítica feroz provém de nossos cus. Nosso cu é nosso poder. Tantas interdições, fantasias religiosas e coloniais sobre nossos cus. A antropofagia já não nos une mais. Já os comemos como condição imposta violentamente pela educação civilizadora colonial. Agora os vomitamos e cagamos. Ao sul do mundo, ao cu do mundo, ao cu do corpo. $^{5}$

\section{Estudos da performance $\mathrm{x}$ performatividade de gênero}

A performance artística de Pêdra Costa poderia ser analisada por vários vieses, a exemplo de seu caráter decolonial e transgressivo, mas aqui o meu propósito é perguntar o seguinte: é possível separar a performatividade de gênero dissidente de Pêdra Costa de sua performance artística? E invertendo a sentença de Butler, seria um erro reduzir sua performance artística à sua performatividade de gênero dissidente?

Como veremos a seguir, ao contrário do que sugere a sentença de Butler, os estudos da performance evidenciam as profundas relações entre performance e performatividade, o que nos sugere também a dificuldade em separar performance de gênero da performatividade de gênero do/a artista. Isso porque uma das caraterísticas fortes de muitas performances é a implicação intensa do/a artista naquilo que está sendo performado (Carlson, 2010; Cohen, 2002; Fabião, 2013). Os textos clássicos de Allan Kaprow (2016), primeiro a conceituar a ideia de happening (acontecimentos) na performance, também destacam a importância não só do

${ }^{5}$ A performance completa pode ser assistida em https://repositori.macba.cat/handle/11350/44427 - Acesso 4 abr. 2020. Uma primeira versão do Manifesto O Cu do Sul - The Kuir Sauvage foi publicado na revista Concinnitas, ver Costa (2016). Todas as traduções foram realizadas pelo autor deste texto. 
corpo, mas da vida cotidiana do artista em suas obras. Ele também defendia, assim como vários/as outros/as, que qualquer objeto do cotidiano poderia ser utilizado nas obras artísticas e aqui eu incluiria que as primeiras expoentes da arte feminista levaram isso ao pé da letra e incluíram a sua própria performatividade de gênero como obra artística 6 .

Inicialmente eu acreditava que existia uma confusão conceitual tanto nos estudos do campo das artes quanto nos estudos de gênero em torno das noções de performance e performatividade. Mas os pioneiros textos de Kaprow (2016), as reflexões de Josette Féral $(2015,2009)$ e outros/as autores/as, me ajudaram a entender que, na verdade, não existe uma confusão entre performance e performatividade no campo das artes, o que existem são complexas relações entre essas noções que não nos permitem fazer distinções rígidas entre elas.

Kaprow (2016), ao tentar estabelecer diferenças entre os happenings e as obras de teatro (naquele momento, na década de 60, isso parecia possível, mas como veremos a seguir essas fronteiras também rapidamente se diluíram7), explica que os primeiros são gerados no momento em que acontecem, pois eles não possuem “nem um argumento nem uma 'filosofia' evidente, e se materializam de maneira improvisada, à semelhança do jazz e boa parte da pintura contemporânea, onde não sabemos exatamente o que vai ocorrer na continuação" (Kaprow, 2016, p. 62).

O que caracterizava os happenings de então era a improvisação, a falta de um texto rígido para o artista seguir, o uso de espaços não tidos como artísticos, a espontaneidade, o azar e a sua impermanência, ou seja, só ocorriam uma vez, sem ensaios e sem a participação de profissionais, a variedade de tempo, pois podem durar horas ou alguns minutos, o uso de diversos materiais cotidianos abordados de maneira menos artística e o mais prática possível. Ou seja, os happenings são

\footnotetext{
${ }^{6}$ A lista de artistas poderia ser longa. A exposição e catálogo Mulheres radicais: arte latino-americana, 19601985 (2018) apresentaram obras de várias artistas que poderiam ser lidas dessa forma. Destaco, por exemplo, os trabalhos de Letícia Parente (Preparação 1, 1975 e Tarefa 1, 1982) em que ela questiona os padrões de feminilidade e papéis de gênero atribuídos às mulheres donas de casa. Já numa perspectiva mais dissidente, os trabalhos de Ana Mendieta (como Transplante de pelos faciais, 1972) questionavam as normas de gênero.

Conforme conta Roselee Goldberg (2007), a performance, no seu início, por volta de 1910, com os futuristas, tinha relação com o teatro. Aos poucos essa relação foi rompida e refeita, em outros moldes, nos anos 1980, quando a linha divisória entre o teatro tradicional e a performance tornou-se indistinta.
} 
(ou eram) atos performativos, no sentido de John Austin (1990), porque criam aquilo que enunciam.

Décadas depois das primeiras práticas e teorizações em torno da arte da performance, nas quais os happenings tiveram uma importante colaboração, Josette Féral propôs a ideia de teatro performativo e, para isso, inicialmente também tentou estabelecer diferenças entre performance e teatro. Depois, se deu conta de que uma das coisas já contaminou a outra e, hoje, é muito difícil estabelecer distinções em boa parte das obras que se apresentam tanto como performances quanto como teatro. Ela propôs chamar certo tipo de teatro de performativo porque a noção de performatividade estaria no centro do seu funcionamento. Féral pretende, com isso, se contrapor a ideia de teatro pósdramático, desenvolvido anos antes por Hans-Thies Lehmann (2007).

Para realizar a sua reflexão, que se tornou muito famosa, ela retoma a noção de performance tal como concebida por Richard Schechner (2012), teórico que trabalha uma noção bem ampliada de performance que inclui todos os domínios da cultura, de viés mais antropológico, em contraposição à noção defendida por Andreas Huyssen, que trata da performance no seu sentido puramente artístico. Féral demonstra como a "prática da performance teve uma incidência radical sobre a prática do teatro como um todo" (Féral, 2015, p. 117).

Ao analisar uma série de obras teatrais, a autora evidencia como o ator do teatro performativo (que Lehmann chamou de pós-dramático), diferente do teatro dramático clássico, se transformou em um performer. O ato de um ator entrar e sair de uma personagem aos olhos do público, por exemplo, constitui, diz Féral, um ator que parece, antes de tudo, como um performer. Ao analisar a peça O quarto de Isabella, de Jan Lauwers, ela diz:

O início da narração sublinha, de maneira muito clara, a colocação em primeiro plano da execução das ações por parte dos performers que cantam, dançam, contam, às vezes encarnam a personagem, mas que saem dela completamente na sequência. O ator aparece aí, antes de tudo, como um performer. Seu corpo, seu jogo, suas competências técnicas são colocadas na frente. O espectador entra e sai da narrativa, navegando ao sabor das imagens oferecidas ao seu olhar. O sentido aí não é redutor. A 
narrativa incita uma viagem no imaginário que o canto e a dança amplificam. Os arabescos do ator, a elasticidade de seu corpo, a sinuosidade das formas que solicitam o olhar do espectador em primeiro plano, dependem da proeza e, longe de buscar um sentido para a imagem, o espectador se deixa prender por essa performatividade em ação. Ele performa (Féral, 2015, p. 120 - grifos da autora).

Féral analisa uma série de obras performativas que não são verdadeiras nem falsas, que colocam em cena o processo de realização (algo central em boa parte das performances), que valorizam o risco de o ato performativo dar certo ou não, recusam a representação mimética, desconstroem a realidade, os signos, os sentidos e a própria linguagem. "Mais que o teatro dramático, e como a arte da performance, é o processo, ainda mais que o produto, que o teatro performativo coloca em cena" (Féral, 2015, p. 124). Além disso, a autora também destaca que no teatro performativo, assim como na performance, a subjetividade do performer e sua vivacidade é colocada no centro da obra. Não existe o distanciamento do ator para com a cena. Não existe representação, pelo menos não no sentido clássico. Não se valoriza aqui o ator que representa um personagem distante de sua vida ${ }^{8}$. Pelo contrário, voltamos aqui na valorização total da vida do/a ator/atriz em cena. Por fim, Féral termina seu texto dialogando com a ideia de happening:

Nessa forma artística, que dá lugar à performance em seu sentido antropológico, o teatro aspira a fazer evento (acontecimento), reencontrando o presente, mesmo que esse caráter de descrição das ações não possa ser atingido. A peça não existe senão por sua lógica interna que the dá sentido, liberando-a, com frequência, de toda dependência, exterior à uma mimese precisa, a uma ficção narrativa construída de maneira linear. O teatro se distanciou da representação (Féral, 2015, p. 131 - grifos da autora).

\footnotetext{
${ }^{8}$ A análise de Féral difere em alguns aspectos das realizadas por Renato Cohen (2002). No pioneiro livro A performance como linguagem, cuja primeira edição é de 1989, ele já demonstrava como é difícil definir o que é a performance dentro ou fora do campo das artes. "De uma forma cronológica, podemos associar o início da performance com o século XX e o advento da modernidade. A rigor, antropologicamente falando, pode-se conjugar o nascimento da performance ao próprio ato do homem se fazer apresentar (a performance é uma arte cênica) e isso se dá pela institucionalização do código cultural” (Cohen, 2002, p. 34). Ainda que o trabalho de Cohen ofereça uma rica reflexão sobre características gerais da performance artística, ele era rígido em pensar a relação entre performer e a performance. "E é importante clarificar-se essa noção; quando um performer está em cena, ele está compondo algo, ele está trabalhando sobre sua "máscara ritual" que é diferente da sua pessoa do dia-a-dia. Nesse sentido, não é lícito falar que o performer é aquele que "faz a si mesmo" em detrimento do representar a personagem. De fato, existe uma ruptura com a representação, como demonstraremos no capítulo seguinte, mas este "fazer a si mesmo" poderia ser melhor conceituado por representar algo (a nível de simbolizar "em cima de si mesmo") (Cohen, 2002, p. 58 - aspas do original).
} 
Se o teatro se distanciou da representação, na performance ela quase nunca foi um objetivo. "É que o performer não representa. Ele é. Ele é isso que ele apresenta. Ele não é nunca uma personagem. Ele é sempre ele próprio, mas em situação. Ele fabrica signos brutos sem mediações. Nós não estamos no domínio do um. O performador não tem duplo. [...] ele é sensação e não emoção", diz Féral (2015, p. 146).

Janaina Fontes Leite (2017) mostra que essa discussão, emergente nos estudos do teatro no Brasil, tem sido abordada no teatro de várias maneiras, através, por exemplo, do conceito de "teatro do real", "teatro documentário" ou o que ela propõe como "autoescrituras performativas". No entanto, no Brasil, é Matteo Bonfitto (2013) quem complexificou ainda mais a questão e me inspirou, como será possível ver mais adiante, a pensar as diferenças entre performance de gênero e performatividade de gênero.

Bonfitto (2013) faz uma sólida e extensa análise de performances e peças teatrais e de textos teóricos de diversos períodos históricos para evidenciar, entre outras coisas, que a oposição entre representar e presentar não foi inaugurada nas artes com o surgimento das reflexões em torno do performativo. Ele lembra que as já antigas discussões entre teatral e antiteatral, que envolveram nomes como Michael Fried, Friedrich Nietzsche, Walter Benjamin e Theodor Adorno, evidenciam que a atitude antiteatral não surgiu com o advento da performance art.

Além disso, Bonfitto (2013) também demonstra que outras distinções utilizadas para diferenciar o teatro da performance, ou teatralidade e performatividade, entre cotidiano e extracotidiano, referencialidade e autorreferencialidade ou representação e presentação muitas vezes são dissolvidas e estão presentes, ainda que em níveis e formas diferentes, tanto no teatro quanto na performance contemporânea. Ele pergunta, por exemplo: “A representação, a fim de obter os efeitos desejados, mesmo enquanto representação, não necessita do performativo? [...]. O ator, mesmo quando representa um personagem, não pode ao mesmo tempo ser um veículo catalisador de fluxos simultâneos??” (Bonfitto, 2013, p. 184).

9 Essa seria, como defende Féral, autora com a qual Bonfitto também dialoga, uma característica do performer. 
A saída encontrada por Bonfitto (2013) foi entender, como o próprio título do seu livro aponta, o que existe entre o ator e o performer. Mais do que apontar as diferenças entre essas duas práticas artísticas, o pesquisador esteve interessado em "percorrer um intricado labirinto de espelhos multifacetados, é como tentar capturar um caleidoscópio em constante movimento e transformação" (Bonfitto, 2013, p. 162) que, em certo momento, ele diz se assemelhar à ideia de rizoma, de Deleuze e Guattari (Bonfitto, 2013, p. 119), ou à Fita de Moebius.

Mesmo sem obter respostas definitivas, o trabalho desenvolvido por
pesquisadores e artistas como Lehmann, Féral, Fischer-Lichte, Artaud,
Grotowski, Brook, Fusco, Gómez-Peña e Abramovic contribui em diferentes
níveis para a percepção do performativo e do teatral não como elementos
que se excluem necessariamente, mas como polos que se afastam e se
atraem. Como na fita ou banda criada por Moebius, em muitas
manifestações artísticas contemporâneas das quais o ator e o perfomer
são parte integrante, é impossível saber qual se mostra e qual permanece
como força latente, se o teatral ou o performativo (Bonfitto, 2013, p. 185-
186).

E onde entra a discussão da performatividade de gênero nisso tudo? Ao que parece, e vários textos dão a entender isso (Carlson, 2010, Féral, 2015, Mostaço, 2009), as discussões de Judith Butler ajudaram a proliferar, nos estudos das artes, a ideia de performatividade porque, ao final, todos/as recorrem às ideias iniciais de Austin e às posteriores críticas e colaborações de Derrida ao conceito de atos performativos. No entanto, como já deu para perceber, quando, nos estudos das artes, as pessoas pesquisadoras falam de performatividade, elas não estão necessariamente usando o conceito do modo como Butler o utiliza.

Como destaquei no início deste texto, ao fazer uma distinção entre performance e performatividade, Butler destaca que, ao pensar nas drags, estava muito mais interessada na paródia de gênero por elas produzida do que em tê-las como exemplo de performatividade de gênero. Navarro, que estudou a teoria da performatividade de gênero em Butler, também destaca que, em Cuerpos que importan, ela faz um esforço de distinguir

[...] entre um modelo de gênero limitado à noção de performance e outro que se desenvolve nos termos previstos na teoria da performatividade de 
gênero. A distinção é importante posto que, onde a paródia implica um modelo voluntarista, fundamentalmente teatral, da representação genérica, a performatividade recorre a uma ampla - e variada - tradição textual e filosófica que desafia, entre outras pretensões teóricas, o ilusório controle intencional pleno das citações da norma em virtude das quais se constitui o sujeito. Podemos assinalar, em consequência, não só - com Butler - a performance como um aspecto ou momento da performatividade (e não como seu limite), mas, também a paródia como momento de ressignificação e, em consequência, da política (e não como seu limite) (Navarro, 2012. p. 32).

Navarro (2012) avança um pouco ao entender a performance como um momento da performatividade de gênero. Ainda assim, se contrapormos as reflexões de Butler e Navarro (2012) com as de Kaprow (2016), Féral (2015) e diversos/as artistas da arte feminista e/ou das dissidências sexuais e de gênero, da qual faz parte Pêdra Costa, veremos uma grande diferença no que cada um/a entende por performance, seja nos textos ou nas obras que criam. Para o/a teórico/a da performance e diversos/as artistas, performance não é paródia e nem se explica somente através de um modelo voluntarista ou de representação.

Para os estudos e artistas da performance, a performance não inaugurou (Bonfitto, 2013), mas produziu um novo capítulo na história da arte para romper com a separação entre vida e obra e problematizou profundamente a ideia de representação. Pêdra Costa não faz uma paródia, não separa vida e obra, não representa uma personagem. Pêdra performa seu gênero e sexualidade dissidente, transforma isso em arte e transforma isso em sua vida. Não é por nada que reivindica uma teoria que passe pelo corpo, inclusive pelo cu.

Além disso, se paródia pode ser aplicada para as drags, para várias outras artistas como Pêdra Costa e tantas outras aposto que isso seria totalmente contraproducente ou até ofensivo ${ }^{10}$. A questão central é: pelo fato da performance, enquanto prática artística, recusar a representação e colocar no centro a vida, o

\footnotetext{
${ }^{10}$ Ofensivo caso as pessoas entendam as parodistas como inimigas da originalidade ou como praticantes de uma arte menos importante, o que não é o caso da pesquisadora Linda Hutcheon (1985), com quem compactuo em suas interessantes reflexões sobre a paródia, especialmente na literatura. Para ela, "ironia e paródia tornaram-se os meios mais importantes para criar novos níveis de sentido - e ilusão” (p. 46). A autora problematiza e/ou diferencia as relações entre paródia, ironia, pastiche, sátira, alusão e plágio e defende que a paródia se constitui como uma "repetição com diferença" (p. 50).
} 
corpo e a subjetividade da própria pessoa artista, torna-se impossível separar a performatividade de gênero da pessoa artista da sua performance. Isso vale para muitas performances, mas se torna ainda mais nítido, importante e político para as performances feministas, sejam elas ligadas às dissidências sexuais e de gênero ou não.

Mas isso, paradoxalmente, não quer dizer que a performance de gênero e a performatividade de gênero da pessoa artista sejam exatamente a mesma coisa. Ainda que, em uma performance, o/a artista traga a sua vida e gênero para o centro de sua obra, especialmente nas artes feministas e/ou das dissidências sexuais e de gênero, isso não quer dizer que isso será feito exatamente da mesma forma como ele/ela performa o seu gênero em outros momentos de sua vida. Inclusive a própria repetição, dentro ou fora de cena, sempre se dá com alguma diferença. Além disso,

Lembremos que se toda atividade humana pode ser considerada como performance, estando a distinção no fato de que na performance cotidiana o sujeito não está sempre consciente do que é nem do que se mostra, ao contrário de todas as performances artísticas, rituais, esportivas ou mesmo aquelas que consistem na demonstração de excelência em um campo (Féral, 2009, p. 79).

Inspirado em Bonfitto (2013), na sua discussão sobre o ator e o performer, penso que aqui também existem dois polos que ora se afastam e ora se atraem, se contaminam, para usar um termo em voga em época de coronavírus, se conectam rizomaticamente de modo que, em muitos casos, fica difícil estabelecer onde termina um e começa outro. Como diz Bonfitto (2013), ao tratar sobre performance e teatro, sugiro que seja mais interessante pensar o que está entre performance de gênero e performatividade de gênero, ao invés de pretender especificar, de forma estanque, as suas diferenças.

Nos últimos anos, procurei ler todos os textos de Butler para ver se em algum deles ela dialoga com algum estudo da performance. Para uma pesquisadora tão interdisciplinar, isso não seria impossível. Encontrei um texto, originalmente publicado em 1988, em que ela cita, ainda que rapidamente, dois conhecidos 
teóricos da performance (Richard Schechner ${ }^{11}$ e Victor Turner). No entanto, ela continua a operar uma distinção rígida entre o que ocorre no palco e na rua e ainda acredita que seja possível pensar que no palco ocorre "só atuação", ideia que, como vimos, tem sido exaustivamente refutada nos estudos do campo das artes. Vejamos:

[...] ver uma travesti subir ao palco pode suscitar prazer e aplausos, enquanto vê-la sentada ao nosso lado no ônibus pode despertar medo, raiva e até mesmo violência. Fica claro que, em ambas as situações, as convenções que medeiam a proximidade e a identificação são bastante diferentes. Pretendo comentar essa distinção provisória em dois sentidos. No teatro é possível dizer "isso é só atuação", e assim desrealizar o ato, ou seja, separar completamente a atuação da realidade. Com essa distinção, reforça-se o sentido do que é real face a esse desafio temporário a nossas premissas ontológicas quanto a configurações de gênero; as várias convenções que anunciam que "isso é apenas uma peça" nos permitem traçar linhas rígidas entre a performance e a vida. Na rua ou no ônibus, o ato se torna perigoso, se realizado, porque simplesmente não há convenções teatrais delineando o caráter puramente imaginário do ato; não existe, na rua ou no ônibus, qualquer presunção de que o ato é diferente da realidade. $O$ efeito perturbador do ato deriva da ausência de convenções que facilitem essa demarcação. De fato, há um teatro que tenta questionar ou mesmo romper com as convenções que demarcam a separação entre o imaginário e o real (Richard Schechner mostra isso muito claramente em Between Theatre and Anthropology). No entanto, nesses casos, confronta-se o mesmo fenômeno, ou seja, o fato de que o ato não é contrastado com a realidade, mas constitui uma realidade nova em um sentido, uma modalidade de gênero que não pode ser facilmente assimilada às categorias pré-existentes que regulam a realidade de gênero (Butler, 2018, p. 12).

Nas suas produções mais recentes, embora aparente estar preocupada com outras questões, Butler continua o esforço de pensar, ampliar e qualificar a sua teoria da performatividade. Nem sempre ela está pensando especificamente em gênero, mas em questões mais amplas que envolvem a performatividade da política (Butler, 2017a).

No texto que finaliza o livro Cuerpos que importan, Butler volta a falar sobre as drags e sobre uma série de ações performativas realizadas nas ruas por coletivos do ativismo queer para chamar atenção das autoridades para os problemas do HIV-

${ }^{11}$ Schechner (2013, p.153) cita esse mesmo texto de Butler, a elogia e não parece ver problemas na distinção que ela faz entre a performance da travesti no palco e a performatividade da travesti na rua. 
Aids. No entanto, isso a faz concluir, apenas, que não se pode opor o teatral ao político.

Eu diria que é impossível opor o teatral ao político dentro da política queer contemporânea: a "atuação" hiperbólica da morte na prática dos "die-ins" e a "exterioridade" teatral mediante a qual o ativismo queer rompeu com a distinção encobridora entre o espaço público e o espaço privado fizeram proliferar lugares de politização e uma consciência da aids em toda a esfera pública (Butler, 2008, p. 327).

Sobre a atuação das drags, ela volta a dizer:

Em nenhum sentido podemos chegar a conclusão de que a parte de gênero que se "atua" é a "verdade" do gênero; a "atuação" como um "ato" limitado se distingue da performatividade porque esta última consiste em uma reiteração de normas que precedem, obrigam e excedem ao ator e, nesse sentido, não podem considerar-se o resultado da "vontade" ou a "eleição" do ator; ademais, o que se "atua" serve para ocultar, se não já para renegar aquilo que permanece sendo opaco, inconsciente, irrepresentável. Seria um erro reduzir a performatividade à manifestação ou atuação de gênero (Butler, 2008, p. 328-329).

Concordo que é um erro reduzir a performatividade à "atuação de gênero". No entanto, também é um erro pensar que toda performatividade de gênero seja distinta da performance de gênero realizada por uma pessoa artista, seja ela artista drag ou não. Mesmo a drag, quando está montada, não consegue fazer desaparecer por completo a sua performatividade de gênero cotidiana. Aliás, muitas vezes a artista nem pretende apagar essas suas características fora da cena. Além disso, na medida em que se torna conhecida, não é incomum que ela, mesmo desmontada, guarde traços de sua "personagem" no dia a dia e, inclusive, muitas vezes seja chamada na rua pelo seu nome artístico. A performance drag exige algum grau de montação, que varia em intensidade e objetivo a ser alcançado, o que não ocorre da mesma forma em outras performances de gênero como as de Pêdra Costa, que não se monta, no sentido drag, mas usa a sua performatividade de gênero e/ou sexualidade como eixo central de sua obra. Ou seja, esfumaça as fronteiras entre performance e performatividade de gênero.

Em outro texto bem mais recente, na verdade uma conversação com Athena Athanasiou para discutir o performativo na política, Butler (2017b) cita 
longamente uma performance de Regina José Galindo, da Guatemala, intitulada Quien puede borrar las huellas? Butler considera essa performance como uma forma militante de arte corporal e, entre outras coisas, diz:

Seu corpo foi tomado e movido por forças que são muitos fortes para ser combatidas. O corpo é uma memória que ganha vida, por dizer de alguma maneira, uma memória que retira a mão que pode apagar essas linhas. E apesar de que nesse trabalho o corpo sofre, a queda é limitada e superada por uma força externa, o corpo da performer, em certo sentido, subsiste, sobrevive, mostrando e colocando nisso uma história social (Butler, 2017b, p. 209).

Marvin Carlson (2010) explica como a teoria da performatividade de gênero de Butler passou a interessar aos estudos da performance e aos/às artistas. Ele diz que, embora as reflexões da filósofa não estejam focadas na arte da performance, mas na dimensão performativa da vida, as suas abordagens se mostraram sugestivas para o campo artístico, em especial para o que ele chamou de "performances de resistência" produzidas dentro de perspectivas feministas. E isso, conta o autor, acabou por gerar desafios às pessoas e à teoria da performance.

Ironicamente, quanto mais conscientes os teóricos se tornaram da centralidade da performance na construção e manutenção das relações sociais em geral e dos papéis de gênero em particular, mais difícil se tornou desenvolver uma teoria e uma prática da performance que pudessem questionar ou desafiar essas construções (Carlson, 2010, p. 195).

Ana Bernstein (2004) lembra que o próprio Austin excluiu de sua teoria dos atos de fala as representações teatrais e literárias pois, para ele, as linguagens empregadas nesses casos não seriam as usadas nas circunstâncias comuns, seriam "vazias ou nulas". A autora diz que Austin revelou aí um preconceito para com as artes. No entanto, em seguida, Bernstein também aponta que Judith Butler exerceu influência nos estudos da performance com sua teoria da performatividade, mas ela não percebe que a filósofa também acabou por considerar as performances artísticas como distintas da performatividade de gênero.

Apesar de defender que a teoria da performatividade impactou os estudos da 
performance e expandiu o próprio conceito de performance, quando Bernstein trata de um texto de Peggy Phelan, intitulado Andy Warhol - performances of death in America, acaba por adotar a mesma distinção entre performance e performatividade presente em Butler. Phelan teria refletido sobre a diferença entre a morte como um fenômeno repetitivo na sociedade de massa, que ele teria nomeado de performatividade da morte, e nossa própria morte individual.

Para Phelan, a morte anônima, coletiva, prepara, ensaia cada um de nós para nossa experiência única, individual, que é a performance de nossa própria morte. Ela diferencia entre performance e performatividade, entre um ato singular e um ato que é apreendido como uma recorrência, uma citação de atos similares anteriores (Bernstein, 2004. p. 66).

Ora, aqui caberiam várias considerações para problematizar essa distinção. Escrevo esse texto em confinamento na Espanha em função da pandemia do novo coronavírus. Enquanto o governo espanhol determinou o confinamento de toda a população por, inicialmente, 15 dias, leio na imprensa e nas redes sociais que o presidente Jair Bolsonaro insiste em não fazer o mesmo, alegando inclusive que tudo não passa de uma histeria ou uma "gripezinha". Poderia dar outros vários exemplos em que a nossa morte individual não se constitui em um ato singular. Nossas vidas e nossas mortes são políticas, como muito bem evidenciou Foucault (1993) com o seu conceito de biopolítica e Achille Mbembe (2018) com o conceito de necropolítica.

\section{Para concluir}

Mas, enfim, o que apreendemos com toda essa discussão? Para os estudos e artistas da performance, distinguir performance e performatividade é complicado porque essa última se refere ao próprio fazer da primeira. Como explica Féral (2009), nas artes a performatividade é marcada pelo princípio da ação, ela mostra um fazer em cena. A repetição na arte se constitui em uma preparação consciente para a performance. Também é complexo diferenciar performance de gênero e performatividade de gênero porque as obras e as vidas dos/as artistas são 
indissociáveis e, muitas vezes, a própria identidade de gênero e sexual é o motor das performances. Mostaço (2009, p. 21) explica que, se por um lado a performance artística está interessada numa "situação extra cotidiana que visa, primordialmente, desestabilizar tudo que é repetitivo ou corriqueiro", por outro lado,

para fazer frente à repetição, a performance art costuma recorrer, com frequência, aos rituais estabelecidos, aos poderes do corpo e suas reverberações, à magia e às práticas primitivas naquela zona pouco clara entre o instintual e o cultural, razão pela qual toma a vida em seus aspectos especificamente performáticos como ponto de incisão e território de exploração (Mostaço, 2009, p. 22).

Já para os estudos de gênero e sexualidade butlerianos, a ideia de performatividade é distinta porque somos constituídos pela repetição das normas de gênero antes mesmo de nossos nascimentos. Por isso, para Butler, foi importante diferenciar a performatividade da performance artística. No entanto, como vimos, os estudos e artistas da performance nos instigam a problematizar essa dicotomia. Curioso é que os estudos queer, que tanto problematizaram as dicotomias sexuais e de gênero, pelo visto ainda não se livraram por completo de alguns binarismos. Como diz Pêdra Costa, inclusive a dicotomia entre teoria e prática precisa ser implodida, é necessário deixar a teoria passar e entrar pelo corpo, não apenas pela cabeça, mas também pelo cu.

\section{Referências}

AUSTIN, John Langshaw. Quando dizer é fazer. Porto Alegre: Artes Médicas, 1990.

BERNSTEIN, Ana. Atos da fala, representação teatral e teorias da performance. Revista Folhetim, Rio de Janeiro, n. 20, p. 58-71, 2004.

BONFITTO, Matteo. Entre o ator e o performer. alteridades, presenças, ambivalências. São Paulo: Perspectiva, 2013.

BUTLER, Judith e ATHANASIOU, Athena. Desposesión: lo performativo en lo político. Buenos Aires: Eterna Cadena Editora, $2017 \mathrm{~b}$. 
BUTLER, Judith. Os atos performativos e a constituição do gênero: um ensaio sobre fenomenologia e teoria feminista. Chão da Feira, Caderno n. 78, p. 1-16, 2018. Disponível em:

http://chaodafeira.com/wp-content/uploads/2018/06/caderno_de_leituras_n.78final.pdf. Acesso em: 4 jan. 2019.

BUTLER, Judith. Cuerpos aliados y lucha politica - hacia uma teria performativa de la asamblea. Buenos Aires: Paidós, 2017a.

BUTLER, Judith. Cuerpos que importan: sobre los límites materiales y discursivos del "sexo". Buenos Aires: Paidós, 2008.

BUTLER, Judith. Críticamente subversiva. In: JIMÉNEZ, Rafael M. Mérida. Sexualidades transgresoras. Una antología de estudios queer. Barcelona: Icária editorial, 2002, p. 55-80.

BUTLER, Judith. Problemas de gênero. Feminismo e subversão da identidade. Rio de Janeiro, Civilização Brasileira, 2003.

CARLSON, Marvin. Performance - uma introdução crítica. Belo Horizonte: Editora UFMG, 2010.

COHEN, Renato. Performance como linguagem. Criação de um tempo-espaço de experimentação. São Paulo: Editora Perspectiva, 2002.

COLLING, Leandro; ARRUDA, Murilo Souza; NONATO, Murillo Nascimento. Perfechatividades de gênero: a contribuição das fechativas e afeminadas à teoria da performatividade de gênero. Cad. Pagu, Campinas, n. 57, p. 1-34, 2019.

COSTA, Pêdra. The Kuir Sauvage. Concinnitas, Rio de Janeiro, ano 17, v. 01, n. 28, p. 355 a 359, setembro de 2016. - Disponível em https://www.epublicacoes.uerj.br/index.php/concinnitas/article/view/25926/18565. Acesso em: 4 abr. 2020.

FABIÃO, Eleonora. Programa performativo: o corpo-em-experiência. Ilinx, Campinas, n. 4, p. 1-11, 2013.

FÉRAL, Josette. Além dos limites: teoria e práticas do teatro. São Paulo: Perspectiva, 2015.

FÉRAL, Josette. Performance e performatividade: o que são os estudos performáticos? In: MOSTAÇO, Edélcio; OROFINO, Isabel; BAUMGÄRTEN, Stephan e COLLAÇO, Vera. Sobre performatividade. Florianópolis: Letras Contemporâneas, 2009, p. 49-86.

FOUCAULT, Michel. Microfísica do poder. Rio de Janeiro: Graal, 1993. 
GOLDBERG, Roselle. A arte da performance - do futuro ao presente. Lisboa: Orfeu Negro, 2007.

HUTCHEON, Linda. Uma teoria da paródia. Ensinamentos das formas de arte do século XX. Lisboa: Edições 70, 1985.

KAPROW, Allan. Entre el arte y la vida. Ensayos sobre el happening. Barcelona: Ediciones Alpha Decay, 2016.

LEITE, Janaina Fontes. Autoescrituras performativas. São Paulo: Perspectiva, 2017.

LEHMANN, Hans-Thies. Teatro pós-dramático. São Paulo: Cosac Naify, 2007.

MBEMBE, Achille. Necropolítica. São Paulo: n-1 edições, 2018.

MOSTAÇO, Edélcio. Fazendo cena, a performatividade. In: MOSTAÇO, Edélcio; OROFINO, Isabel; BAUMGÄRTEN, Stephan e COLLAÇO, vera. Sobre performatividade. Florianópolis: Letras Contemporâneas, 2009, pp. 15-48.

MULHERES RADICAIS: ARTE LATINO-AMERICANA, 1960-1985. São Paulo: Pinacoteca de São Paulo, 2018.

NAVARRO, Pablo Pérez. Parodias de la parodia en Martha Nussbaum y Celia Amorós. In: SOLEY-BELTRAN, Patrícia e SABSAY, Leticia. Judith Butler en disputalecturas sobre la performatividad. Barcelona, Madrid: Egales, 2012, pp. 27-58.

SCHECHNER, Richard. Performance e antropologia de Richard Schechner. Seleção de ensaios organizada por Zeca Ligiéro. Rio de Janeiro: Mauad X, 2012.

SCHECHNER, Richard. Performance studies: an introduction. Nova York: Routledge, 3a ed., 2013.

Recebido em: 06/08/2020

Aprovado em: 21/02/ 2021 